\title{
Traumatic Break of the Ascending Aorta: About a Case
}

\author{
Andrea Perrotti ${ }^{1}$, Abdoulaye Kanté2 ${ }^{*}$, Bréhima Coulibaly², Mamadou Almamy Keita ${ }^{2}$, \\ Drissa Traoré2, Mamadou Diakité ${ }^{3}$, Mariam Daou, Bakary Keita5, Birama Togola², \\ Nouhoum Ongoïba ${ }^{2}$, Harrison Haight ${ }^{1}$, Anne Sophie Lacagne ${ }^{1}$, Julie Ritter ${ }^{1}$, \\ Anne Claire Mogenet ${ }^{1}$, Enrica Dorigo ${ }^{1}$, Camille Durst ${ }^{1}$, Djamel Kaili ${ }^{1}$, François Clement ${ }^{1}$, \\ Sidney Chocron ${ }^{1}$
}

\author{
${ }^{1}$ Service of Thoracic and Cardiovascular Surgery, The University Hospital of Besançon, Besançon, France \\ ${ }^{2}$ General Surgery Department, CHU Point G, Bamako, Mali \\ ${ }^{3}$ Cardiology Department of the CHU of the Point G, Faculty of Medicine and Odontostomatology of Bamako, Bamako, Mali \\ ${ }^{4}$ Service of Neurology, Gabriel Touré Teaching Hospital, Bamako, Mali \\ ${ }^{5}$ Anesthesia Service and Resuscitation Department, CHU Gabriel Touré, Bamako, Mali \\ Email: *kanteim@yahoo.fr
}

How to cite this paper: Perrotti, A., Kanté, A., Coulibaly, B., Keita, M.A., Traoré, D., Diakité, M., Daou, M., Keita, B., Togola, B., Ongoïba, N., Haight, H., Lacagne, A.S., Ritter, J., Mogenet, A.C., Dorigo, E., Durst, C., Kaili, D., Clement, F. and Chocron, S. (2018) Traumatic Break of the Ascending Aorta: About a Case. Open Journal of Thoracic Surgery, 8, 63-67

https://doi.org/10.4236/ojts.2018.84011

Received: September 27, 2018

Accepted: November 20, 2018

Published: November 23, 2018

Copyright $\odot 2018$ by authors and Scientific Research Publishing Inc. This work is licensed under the Creative Commons Attribution International License (CC BY 4.0).

http://creativecommons.org/licenses/by/4.0/

\begin{abstract}
The traumatic break of the ascending aorta is rare. We bring report the case of a 40-year-old man, a victim of accident of the public highway having caused a break of the posterior face of the ascending aorta. The explorations scanno graphique and per operating highlighted this break. The treatment consisted of an edge-to-edge direct suture of the ascending aorta.
\end{abstract}

\section{Keywords}

Traumatic Break, Ascending Aorta, Accident of the Public Highway

\section{Introduction}

The traumatic break of the thoracic aorta (RTA) establishes a medical surgical urgency among which the morbidity and the mortality remain still raised in spite of important progress [1]. The accidents of the public highway establish the first cause of RTA especially with the increase of driving speeds. The second big cause is the fall of a big height consecutive to occupational accidents or of defenestration [2]. It is the pathology which affects preferentially a young, mainly male population [3]. From the topographic point of view, the aortic isthmus, is widely dominant $(90 \%$ - 98\%) [4] [5]. The ascending aorta is more rarely concerned. We bring report the case of a 40 -year-old man, a victim of an accident of 
the public highway, having caused a polytraumatisme with to the thoracic level a break of the ascending aorta.

\section{Observation}

It is about a 40-year-old man, a driver of motorcycle, a victim of an AVP motorcycle VL with high kinetics with frontal impact and antero-posterior thoracic compression.

In the admission, the patient was conscious with a score of Glasgow in 15/15, polypnéique tachycardia and unstable on the hemodynamique plan.

The clinical examination highlighted pains in the palpation of the breastbone, the right collarbone and the right hemi thorax with emphysema under cutaneous. There was also a palpatoire pain at the level of the hypochondria and of the custard tart right.

An abdominal ultrasound showed an effusion of low abundance at the renal died level with bladder full of hematiques urines.

A thoraco-abdominopelvien scanner highlighted at the thoracic level a fracture of the manubrium sternal with effusions pericardique and mediastinal not compressif, a pneumo mediastin, with image of traumatic aneurysm of 2, $2 \mathrm{cms}$ at the level of the posterior wall of the ascending aorta (Figure 1).

It also showed a fracture of the not uncalled-for left collarbone, a fracture of the quotations $\mathrm{K} 3$ to $\mathrm{K} 5$ posterior unifocales without shutter, to the right with bilateral lung bruise of the right upper and lower lobes, a left hemothorax of low abundance. At the abdominal level, there was a straight hepatic bruise without active bleeding, a superior polar fracture of the right kidney with a périrrénal bruise and an arterial blusher.

In front of this break traumatic comment of the later face of the ascending aorta, the surgical treatment by sternotomie was envisaged later arterio-embolisation renal.

Per operating the exploration highlighted: a clear and complete tear of the aortic wall of $3 \mathrm{cms}$, horizontal, in $1 \mathrm{~cm}$ above the Sino-tubular junction compared to the left ostium, the venous bleeding over the beginning of exclusion between the superior vena cava and the right earphone and the tear of the pericardia about $10 \mathrm{cms}$ going of the left superior pulmonary vein to $1 \mathrm{~cm}$ of the edge free of the pericardia compared to the trunk of the lung artery. The coronary ostia was clear and the aortic valve was fine without tear.

We realized:

- after section of the aorta and the regulation of edges an edge-to-edge suture of the ascending aorta by hémisurjets two of proline 4/0.

- The repair of the exclusion of the superior vena cava by two points of proline felted 4/0 and of the pericardia by an over sewing of vicryl $2 / 0$.

The total time of the CEC was of 81 minutes, the duration of the aortic clam page of 26 minutes and the lowest temperature of 34 . The operating consequences were simple with exit of the patient to operating J17 comment. 


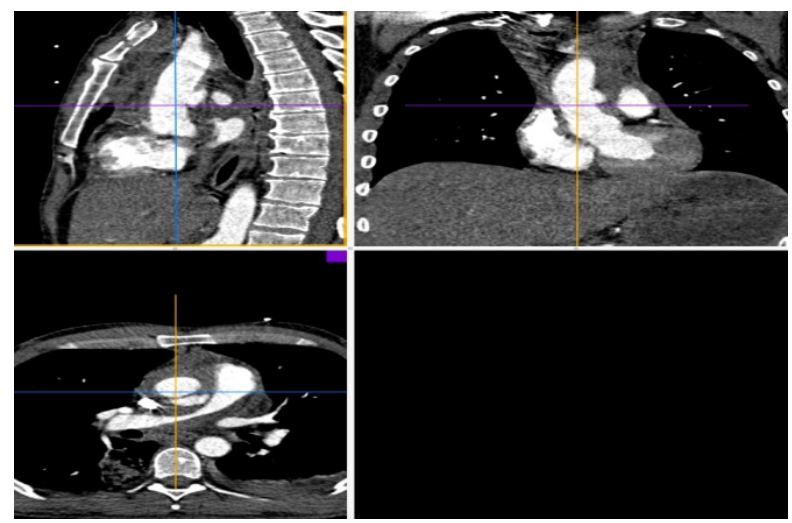

Figure 1. Thoracic CT after injection of the contrast product in axial and sagittal section showing a traumatic aneurism image of $2.2 \mathrm{~cm}$ at the posterior wall of the ascending aorta.

A clinical surveillance and scannographique was recommended for the hepatic and lung bruises.

\section{Discussion}

The traumatic breaks of the aorta are the most frequent hurts of the big vessels of the mediastina [1]. The only forward-looking study realized by Fabian and al [6] showed that approximately $15 \%$ to $23 \%$ of the victims of the road accidents die every year of a traumatic break of the aorta. A percentage from 80 to 85 died immediately on the scene from the accident, during the transport or in emergencies [7] [8].

The mechanisms which come into play in the traumatic hurts of the thoracic aorta are mainly bound to the deceleration or to the acceleration, pulling the laceration of the wall at the level of the zones of transition between the mobile aorta and the stiffer or fixed aorta [8] [9] [10]. So, the aortic isthmus is the most frequent location of the traumatic breaks of the aorta, it represents $90 \%$ to $98 \%$ of the cases in the surgical series and $45 \%$ in $65 \%$ of the cases in the autopsiques series [4] [5]. The downward thoracic distal aorta is the second location in frequency 7 in $12 \%$. The multiple locations: isthmus + downward aorta distal or isthmus + aortic bow are also possible. The location at the level of the ascending aorta is rare, arising only in $0 \%-3 \%$ of the cases. In this particular case, our patient presented a horizontal, net and complete break of the posterior aortic wall of $3 \mathrm{cms}$, in $1 \mathrm{~cm}$ above the Sino-tubular junction compared to the left ostium.

The stake is not to underestimate this rare location of post-traumatic break of the thoracic aorta by analyzing systematically all the aortic axis.

The diagnosis of RTA widely benefited from the generalization of the scanning (TDM).

The direct signs suggestive of break of the aorta whatever is the topography are the mediastinal bruise in continuity with the aorta, the false aneurysm, the irregularity of the aortic outline, and the flap intimal [7]. In our case, there was a flap intimal at the level of the ascending aorta. 
The RTA becomes integrated generally within the framework of a polytraumatism and there are often hurts of the other organs associated. The cranial and abdominal traumas are most frequently associated and in $25 \%$ of cases, these hurts also justify a surgical operation as a matter of urgency. The problem of hierarchical organization of the therapeutic gestures often leaves the perplexed surgeon. These associated hurts influence the global forecast because of their appropriate gravity and/or of their potential worsening by the aortic clam page and the heparinisation.

Seen the instability hemodynamique in the admission and during the evolution, a surgical treatment by sternotomie was realized as a matter of urgency later renal arterio-embolisation by direct suture of the break with a good evolution on a backward movement of 11 months. As for the foyers of hepatic and lung bruises, a conservative treatment was envisaged with favorable evolution on the clinical and radiological plan.

\section{Conclusion}

The break post-traumatic of the ascending thoracic aorta is rare but should not be underestimated and is to be systematically looked for. His diagnosis was improved by the progress of the radiology, in particular the angio scanner as well as the forecast thanks to the speed of the transport towards specialized hospitable structures and the precocity of the coverage.

\section{Conflicts of Interest}

We, authors of this article declare that there is no conflict of interests.

\section{References}

[1] Sullivan, P.R., Wolfson, A.B., Leckey, R.D. and Burke, J.L. (2000) Diagnostic of Acute Thoracic Aortic Dissection in the Emergency Department. The American Journal of Emergency Medicine, 18, 46-50.

[2] Leseche, G., Alsac, J.M. and Castier, Y. (2008) Rupture aigue Post-Raumatique de l'isthme aortique. Journal de Chirurgie, 145, 115-121. https://doi.org/10.1016/S0021-7697(08)73719-0

[3] Tasu, J.P., Kuhi, E., Rocher, L., Miquet, A., Kuoch, V. and Blery, M. (2002) Lésions traumatiques de l'aorte thoracique: Aspect sémiologiques et conduite à tenir. Feuillet de Radiologie, 42, 19-21.

[4] Kodali, S., Jamieson, W.R.E., Leia-Stephens, M., Miyagishima, R.T., Janusz, M.T. and Tyers, G.F.O. (1991) Traumatic Rupture of the Thoracic Aorta. A 20 Year Review: 1969-1989. Circulation, 84, 40-46.

[5] Cowley, R.A., Turney, S.Z., Hankins, J.R., Rodriguez, A., Attar, S. and Shankar, B.S. (1990) Rupture of Thoracic Aorta Caused by Blunt Trauma. A Fifteen-Year Experience. The Journal of Thoracic and Cardiovascular Surgery, 100, 652-661.

[6] Fabian, C., Richardson, J.D., Croce, M.A., et al. (1997) Prospective Study of Blunt Aortic Injury: Multicenter Trial of the American Association for the Surgery of Trauma. The Journal of Trauma: Injury, Infection, and Critical Care, 42, 374-383. https://doi.org/10.1097/00005373-199703000-00003 
[7] Freczko, J.D., Lynch, L., Pless, J.E., Clarek, M.A., Mcclain, J. and Hawley, D.A. (1992) An Autopsy Case Review of 142 Non Penetrating (Blunt) Injuries of the Aorta. The Journal of Trauma: Injury, Infection, and Critical Care, 33, 846-849. https://doi.org/10.1097/00005373-199212000-00009

[8] Von Oppeli, U.O., Dune, T.T., De Groot, M.K. and Zilla, P. (1994) Traumatic Aortic Rupture: Twenty-Year Metanalysis of Mortility and Risk of Paraplegia. The Annals of Thoracic Surgery, 58, 585-593.

https://doi.org/10.1016/0003-4975(94)92270-5

[9] Richens, D., Fiel, M., Neale, M. and Oakley, C. (2002) The Mechanism of Injury in Blunt Traumatic Rupture of the Aorta. European Journal of Cardio-Thoracic Surgery, 21, 288-293. https://doi.org/10.1016/S1010-7940(01)01095-8

[10] Blackmore, C.C., Zweibel, A. and Mann, F.A. (2000) Determining Risk of Traumatic Aortic Injury: How to Optimize Imaging Strategy. American Journal of Radiology, 174, 343-347. 